\title{
Immersed Fatigue Performance of Glass Fibre-Reinforced Composites for Tidal Turbine Blade Applications
}

\author{
C. R. Kennedy ${ }^{1,2} \cdot$ S. B. Leen ${ }^{1,2} \cdot$ C. M. Ó Brádaigh ${ }^{3}$
}

Received: 20 December 2015/Revised: 15 March 2016/Accepted: 17 March 2016/Published online: 18 April 2016

(c) The Author(s) 2016. This article is published with open access at Springerlink.com

\begin{abstract}
This work presents an experimental study on the fatigue of glass fibre-reinforced polymers (GFRP) for use in ocean energy structures, with particular emphasis on the effects of water saturation. Quasi-isotropic specimens with either epoxy or vinyl-ester matrix were reinforced with E-glass or E-CR glass and immersion-aged for a period of up to two and a half years, using a moderately accelerated ageing technique. A number of the specimens were kept under constant tensile stress while immersed. The water-saturated specimens were fatigue tested while immersed in water. Dry specimens of the same materials were also fatigue tested and comparative results are presented. It was established that moisture saturation has a detrimental stress-dependent effect on the fatigue strength of the epoxy/E-glass composite. The measured evolution of specimen stiffness during the fatigue cycles was similar for both dry and water-saturated coupons.
\end{abstract}

Keywords Tidal turbines - Glass fibre blades - Epoxy · Vinyl-ester · Fatigue · Water immersion

\section{Introduction}

Tidal turbines have been at the forefront in the introduction of marine renewable energy technologies due to their repeatable, dependable, power delivery on every tide. Most

S. B. Leen and C. M. Ó Brádaigh are joint senior authors.

C. M. Ó Brádaigh

c.obradaigh@ed.ac.uk

Mechanical Engineering, NUI Galway, Galway, Ireland

2 Marine Renewable Energy Ireland (MaREI) Research Centre, Galway, Ireland

3 Institute for Materials and Processes, School of Engineering, The University of Edinburgh, Edinburgh, Scotland modern tidal turbines have a configuration similar to large wind turbines with two or three aerofoil (or hydrofoil) cross-section blades rotating a horizontal main shaft which powers an electric generator. The higher density of seawater and the lower velocity of tidal currents result in approximately a 100 -fold increase in fluid momentum and therefore tidal turbines are smaller in diameter and rotate more slowly than wind turbines with similar power output. For example a $24 \mathrm{~m}$ diameter tidal turbine rotates at 10 RPM and produces 1.5 MW which is approximately onethird of the diameter and half the rotational speed of a wind turbine with similar power output $[1,2]$. The net effect on the blade structure is higher forces within a smaller envelope which requires maximum possible performance from the materials used to manufacture the blades.

GFRP materials have proven to be the most cost competitive material for wind turbine blades and it is expected that they will be used extensively in marine renewable energy device structures. However, there are concerns about the degradation of composite materials after long immersion in seawater. This paper details a series of investigations into the degradation in strength and stiffness of GFRP materials during long immersion periods.

Glass fibre-reinforced epoxy has a good track record in resisting environmental degradation during marine use and glass fibre-reinforced vinyl-ester is widely used for tanks and pipes carrying both water and corrosive liquids. In some of these applications, the standard boat construction technique of creating a protective barrier (gel coat) between the water and the GFRP may be possible but in many cases it is not. For example, some tidal turbine blade designs are flooded inside to equalise hydrostatic pressure and reduce the effect of pressure variations as the blade rotates in the water column. While a barrier technique may still be possible in this case, it would probably be difficult 
and expensive to implement. Barrier layers may also suffer from either abrasion by sand and grit suspended in the water or from surface cracking at strain levels likely to be experienced by marine renewable energy devices. Finally, it should be noted that it is very difficult to produce a barrier that can actually prevent diffusion of the small amount of moisture (1-2\%) required to saturate GFRP over the 10-20 year lifetime of these devices. Certainly the standard isophthalic polyester gelcoat is not capable of this level of performance [3]. For all these reasons, it is conservative to assume that immersed GFRP will become moisture-saturated relatively early in its life and it is therefore important for a designer to know what degradation in material properties can be expected over the life of the machine component.

The matrix of a polymer-matrix composite has a protective function and invariably will form the outer surface of the GFRP component. In cases where moisture protection is required, very often the outer layer is mostly or entirely matrix material. When seawater comes in contact with a polymer surface, water molecules diffuse into the polymer-matrix material, filling any small voids and hydrolysing any unreacted components of the polymer. The water molecules also bond with elements of the polymer chains reducing crosslink density, thereby reducing both modulus and glass transition temperature [4]. The composite also swells slightly to a level approximately equal to the volume of water absorbed [5]. For laminates with a large surface-to-thickness ratio, the 1-D Fickian equation gives the amount of water absorbed [6]

$M=M_{\text {sat }}\left(1-e^{-7.3\left(\frac{t D}{h^{2}}\right)^{0.75}}\right)$

where $M$ is the percent moisture content at any time $t, M_{\text {sat }}$ is the final percentage saturation level, $h$ is the thickness of the laminate and $D$ is the diffusion constant of the material. The saturation level depends on the particular matrix polymer and varies between approximately $1 \%$ for vinylester to $3 \%$ for epoxy. GFRP composites tend to have near Fickian absorption characteristics with deviations from Fickian behaviour attributed to voids, hydrolysis and molecular relaxation [7]. Void content can vary more than the small percent saturation discussed above so it should be noted that $\%$ weight gain is not a reliable indicator of the change in mechanical properties [8]. Post-cure of the composite, involving soaking for a period at elevated temperatures, is recommended to minimise unreacted components thereby reducing hydrolysis. Post-cure also maximises cross-linking which is important to achieve the maximum strength and stiffness in the material. Post-cure can be expensive, particularly if ovens are used for large structures, but lower-cost heating solutions do exist [9] and for high-performance applications, post-cure is definitely recommended.
While seawater is much more corrosive to many metals than fresh water, studies with SEM on the fracture surfaces of GFRP have found no evidence of salt ions inside the composite material and conclude that the salt ions do not migrate into the composite [10]. Other studies have shown that seawater is slower to diffuse into the matrix but otherwise has similar effects to fresh water [11-13].

As the water diffuses through the polymer matrix, it next encounters the interface zone between the matrix and fibres. The interface between the matrix polymer and the glass fibres is enhanced by silane molecules which are contained in a sizing compound applied to the glass fibres immediately after they are drawn. One end of the silane molecule bonds well to the glass surface and the other end reacts with thermosetting polymers during cross-linking [14]. When a composite material is immersed in water, the size compound absorbs water either through direct contact with the water or from the saturated matrix. This hydrolyses some of the bonds between matrix and fibre, reducing the interfacial bond strength and thereby the overall strength of the material. After failure, the evidence for the reduction in bond strength can be seen by increased fibre pullout. This is particularly evident when accelerated ageing at high temperatures is used [15]. Interlaminar shear strength (ILSS) and $45^{\circ}$ off-axis tests are used as an indication of changes in interface bond strength and tests on GFRP laminates have shown reductions of 8 to $37 \%$ after ageing in room temperature water $[3,16]$. Studies have shown that most of the bond strength recovers upon redrying the composite material, particularly when the initial loss in bond strength was due to high temperature ageing [3, 17].

Having diffused through the matrix and interface zone, the water molecules may finally come in contact with the glass fibre surface. Water is detrimental to the strength of naked (unsized) glass fibres due to the occurrence of stress corrosion cracking (SCC). This occurs when water molecules migrate to the tip of cracks or flaws on the surface of glass that is under stress and accelerate the cracking process [17]. The silane-coupling agents mentioned earlier were developed with an ability to bond strongly to the glass fibre surface and this reduces the interaction of moisture with the glass, preventing or reducing SCC in humid atmospheres. However, when GFRPs are immersed in water for long periods they absorb more water than would be absorbed from air at normal humidity levels. This means that there is more water available at the interface and the protective effect of the silane may not be sufficient to prevent SCC from occurring, particularly at higher stress levels or higher temperatures. Some studies on SCC in water-aged composites with E-CR fibres show that, at room temperature, the strains needed to precipitate SCC activity are at or above the maximum fatigue strains $(1.5 \%)$ found 
in GFRP fatigue-life curves [18]. When the temperature of the ageing water increases, e.g. above $50{ }^{\circ} \mathrm{C}$, it stimulates increased chemical activity and in combination with residual stresses in the fibre can cause SCC of the fibres to occur even in the absence of externally applied stresses. Positive identification of this kind of damage can be provided by SEM; it would also be suspected if GFRP materials do not regain their strength after re-drying. This has been shown to occur with ageing temperatures as low as $71{ }^{\circ} \mathrm{C}$ [19] but others have found that even in boiling water ageing effects are mostly reversible [20].

A corollary to the recommendations for post-cure mentioned earlier is that laminates will post-cure if placed in warm water. It is therefore important that one does not compare mechanical properties taken without post-cure to those obtained from laminates inadvertently post-cured via immersion in warm or hot water. In the latter case, any degradation due to water immersion may well be offset (at least partially) by the increase in performance due to the unintentional post-cure.

There are quite a few reports of quasi-static tensile testing of water-saturated GFRP laminates in the literature and as a group they generally show reductions in tensile strength of between 25 and $50 \%$ due to water saturation. On the other hand, there are relatively few investigations of fatigue testing water-saturated GFRP and fewer still which report fatigue life comparisons between the wet and dry conditions. Those reports show up to a $20 \%$ reduction in tension-tension ( $R=0.1$ ) fatigue strength of water-saturated unidirectional laminates [10] and up to $40 \%$ reduction in bending fatigue strength [23]. This work therefore complements those studies by reporting on fatigue testing of multi-directional laminates (QI) in both dry and watersaturated conditions.

Segovia et al. [21] have tested the effect of an applied bending stress on an orthophthalic polyester/E-glass laminate immersed in room temperature seawater. Higher stress levels (44\% of UTS) resulted in increased water absorption $(24 \%)$ but only caused modulus and bending strength to reduce by $7 \%$ relative to unstressed specimens immersed for the same time. Other tests, however, found no additional loss in strength or modulus due to an applied bending stress (20\% of ultimate) for isophthalic polyester/ E-glass and vinyl-ester/E-glass samples immersed for 2.2 years in $30{ }^{\circ} \mathrm{C}$ water [22]. No reports have been found of fatigue strength testing after combined immersion and stress ageing. An experimental study of fatigue strength testing after combined immersion and tensile stress ageing was conducted as part of the work described in this paper.

This paper deals with an experimental investigation of the water saturation effects discussed above. Modelling of saturated laminates will be discussed in a later paper. The specific objectives for this work were (i) to manufacture high-quality laminates, for use in a tidal turbine blade, (ii) to perform acceleration ageing on these laminates at a low temperature in order to mimic the water saturation level found in an operating tidal turbine blade, (iii) to investigate the effect of that saturation on the tensile and fatigue strength of the materials, (iv) to determine the effect of a constant stress during the immersion ageing process and finally, (v) to determine the effect of water saturation on the modulus of the material.

\section{Experimental Method}

\subsection{Coupon Manufacture}

Quasi-isotropic layups (shown in Fig. 1) of non-crimp E-glass and E-CR glass were infused with vinyl-ester or epoxy resins using the VARTM (Vacuum Assisted Resin Transfer Moulding) process as described elsewhere [24]. The laminates were oven cured at $80{ }^{\circ} \mathrm{C}$ for approximately $4 \mathrm{~h}$. Table 1 shows details of the different material combinations and the ageing methods to which they have been subjected. These combinations allow comparison between a composite material with a matrix resin which is highly resistant to water (Scott Bader VE676 vinyl-ester) and one with moderate resistance to water but good fatigue resistance (Gurit Ampreg 22 epoxy). They also allow comparisons between composites with water-resistant fibres (ECR, Advantex fibres) and standard E-glass fibres (Ahlstrom, \#42007). In both cases, the fibres were coated with the manufacturers "multi-compatible" sizing which are compatible with polyester, vinyl-ester and epoxy resins.

\subsection{Accelerated Ageing Procedure}

Accelerated ageing has been used to simulate the effect of approximately 20 years in cold $\left(12^{\circ} \mathrm{C}\right)$ seawater by immersing the samples in warm $\left(30^{\circ}\right.$ to $\left.40^{\circ} \mathrm{C}\right)$ water for up to two and a half years. Movement of moisture by diffusion into the polymer resin and damage processes within the

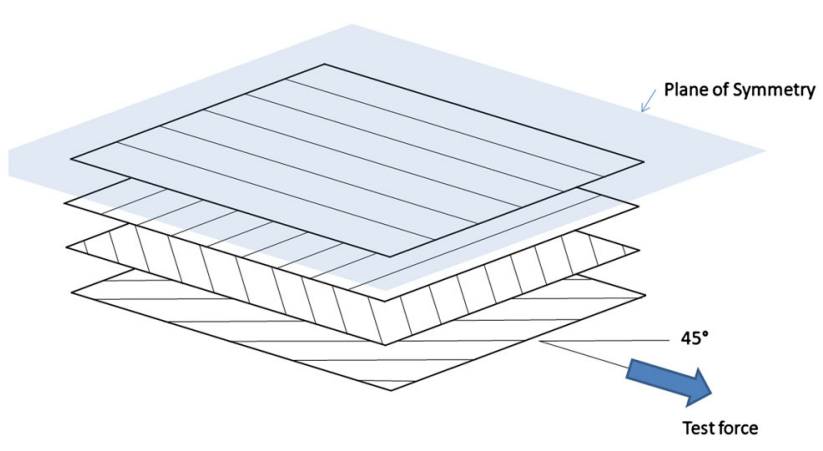

Fig. $1\left( \pm 45^{\circ} / 90^{\circ} / 0^{\circ}\right)$ s Quasi-isotropic layup 
Table 1 Materials tested and ageing procedures used

\begin{tabular}{lllll}
\hline Material & $V_{\mathrm{f}}$ & Thickness $(\mathrm{mm})$ & Immersion ageing & Stress aged \\
\hline Vinyl-ester/E-glass & $50 \pm 2 \%$ & 3.75 & $40{ }^{\circ} \mathrm{C} 30$ months & 21 months \\
Vinyl-ester/E-CR glass & $60 \pm 2 \%$ & 4.22 & $40{ }^{\circ} \mathrm{C} 20$ months & \\
Epoxy/E-glass & $50 \pm 2 \%$ & 3.75 & $30^{\circ} \mathrm{C} 29$ months & \\
\hline
\end{tabular}

composite are accelerated by increasing the temperature, or atomic vibration level, of the material. The Arrhenius law describes how the diffusion rate $\left(k_{\mathrm{d}}\right)$ varies with temperature

$k_{\mathrm{d}}=k_{0} e^{-\frac{E}{R T}}$

where $k_{0}$ is the reference diffusion rate coefficient, $E$ is the activation energy, $R$ is the universal gas constant $\left(8.3145 \mathrm{~kJ} \mathrm{kmol}^{-1} \mathrm{~K}^{-1}\right)$ and $T$ is the temperature in degrees Kelvin.

For a higher temperature in the same material an acceleration factor has been defined as [25]

$F_{\mathrm{H}, \mathrm{L}}=e^{\left[\frac{-E}{R}\left(\frac{1}{T_{\mathrm{H}}}-\frac{1}{T_{\mathrm{ref}}}\right)\right]}$

Selection of the higher temperature $\left(T_{\mathrm{H}}\right)$ to produce a required acceleration factor relative to a given lower (reference) temperature depends on the value of the activation energy $(E)$. Average values of $61 \mathrm{~kJ} \mathrm{kmol}^{-1}$ for the activation energy of vinyl-ester/E-glass composite and $93 \mathrm{~kJ} \mathrm{kmol}^{-1}$ for epoxy/E-glass composite were identified previously [25].

Figure 2 shows a plot of the acceleration factors for epoxy with the above diffusion constant that result from combinations of operating (reference) temperatures and accelerated ageing temperatures. $12{ }^{\circ} \mathrm{C}$ has been chosen as the design operating $\left(T_{\text {ref }}\right)$ temperature for a tidal turbine operating off the coast of Ireland. The graph shows that $30{ }^{\circ} \mathrm{C}$ ageing temperature will cause diffusion-controlled processes to proceed approximately 10 times faster than at

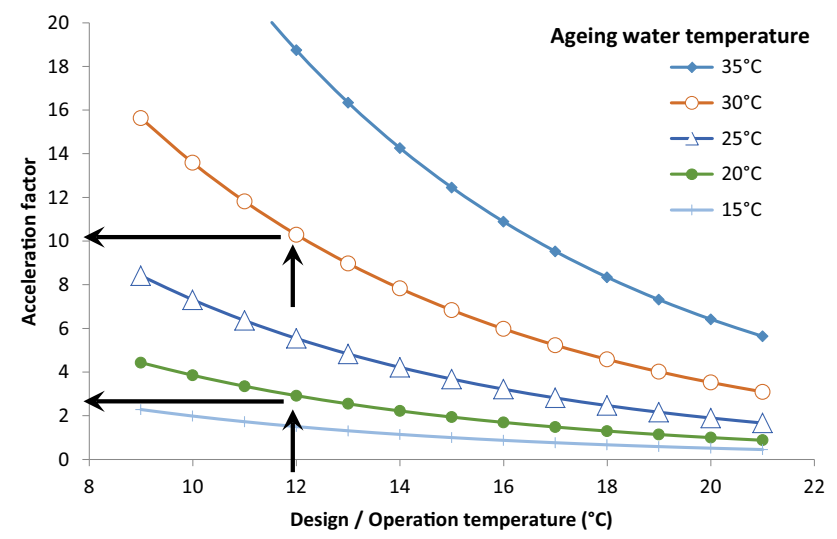

Fig. 2 Predicted acceleration factor for epoxy/E-glass composite due to ageing water temperature
$12{ }^{\circ} \mathrm{C}$. Obviously, a higher temperature would give higher acceleration factors but this must be balanced with the tendency for higher temperatures to cause unintended degradation of the polymer matrix. Figure 2 also illustrates that ageing at room temperature $\left(20^{\circ} \mathrm{C}\right)$ will induce an acceleration factor of approximately 3 over the $12{ }^{\circ} \mathrm{C}$ operating environment. Substituting the diffusion value for vinyl-ester into Eq. 3, shows that the ageing water temperature must be increased to $40{ }^{\circ} \mathrm{C}$ to again give an acceleration factor of 10 . Therefore immersing vinyl-ester glass composite in a water bath at $40{ }^{\circ} \mathrm{C}$ for one year will cause damage equivalent to 10 years in $12{ }^{\circ} \mathrm{C}$ seawater.

Two water baths were prepared using ordinary tap water and heater/stirrer units which ensure that the heated water is circulated throughout the entire tank. One tank contained the epoxy/E-glass coupons and was maintained at $30 \pm 1{ }^{\circ} \mathrm{C}$. The other heated tank contained vinyl-ester/Eglass coupons and was maintained at $40 \pm 1{ }^{\circ} \mathrm{C}$. A room temperature water bath was also used and contained coupons of both materials. Each of the coupons was weighed on a mass balance and the weight recorded to a resolution of 0.001 grams before it was placed in the tank. The average weight of the coupons was $44 \mathrm{~g}$. The coupons were reweighed at intervals during the immersion ageing process and before testing to establish the amount of water that had been absorbed during ageing.

\subsection{Stressed Immersed Testing}

Figure 3 shows a vinyl-ester/E-glass coupon installed in a stressed test configuration. The main component of this rig is a heavy duty die spring with a spring rate of $117 \mathrm{~N} / \mathrm{mm}$. The composite coupon is modified slightly to work with the mechanism by having an 8-mm hole drilled in each end. These holes are spaced at a distance that keeps the spring compressed to a load of $4 \mathrm{kN}$, thereby applying that load to the composite coupon. This resulted in a stress of $42.7 \mathrm{MPa}$ and a strain of $0.21 \%$ in the QI vinyl-ester/E-glass coupons. Before each of the ten coupons was assembled into the stressing rig, they were fatigued in air for 10,000 cycles between 0.8 and $8 \mathrm{kN}$. This load level was chosen to cause cracking in the $90^{\circ}$ plies of the material in order to mimic the damage expected to occur in service [26]. Half (5) of the stressed coupons were immersed in $40{ }^{\circ} \mathrm{C}$ water for 21 months, the other half were stored in insulated conditions at the same temperature as the water bath. 


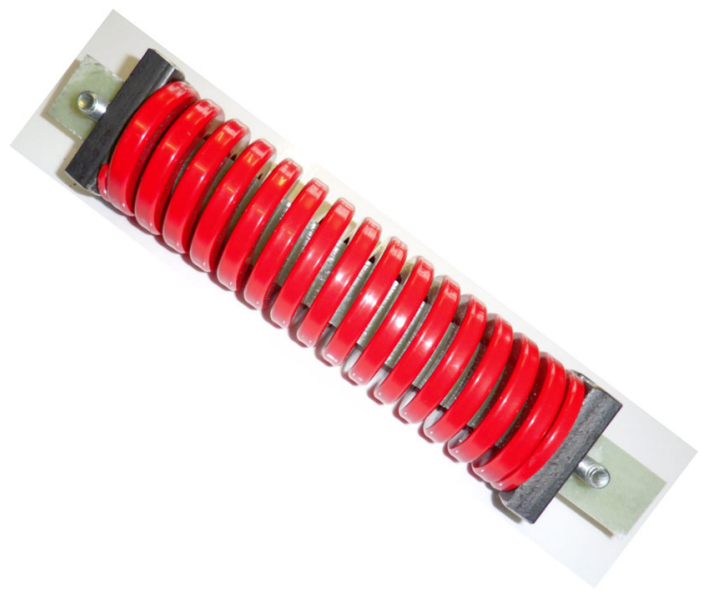

Fig. 3 Stressing mechanism for stress ageing of GFRP coupon

\subsection{Fatigue Test Method}

In general, the fatigue tests were carried out with an Instron 8001 test machine and 8800 controller, applying a sinusoidal force-time history in tension-tension mode $(R=0.1)$, at frequencies of between 3 and $6 \mathrm{~Hz}$. The fatigue test frequency is chosen to ensure that the coupon does not overheat. The $R$-ratio chosen is a standard test that has a simple setup which facilitates installation of the immersed test setup discussed later. After the coupons had been immersion-aged for a number of months, sample initial tests were carried out to develop the test setup. At first, the wet coupons were just removed from the water and fatigue tested in the normal way. However, it was realised that during high cycle fatigue testing (lasting a day or more) the coupons dry out due to the combination of internal heat generation and forced air cooling of the coupons. Allowing the coupons to dry out is not desirable as it has been shown [3] that epoxy and vinyl-ester composites recover most of their original strength when they are re-dried after water saturation. Two methods of keeping the samples immersed in water during the fatigue test, as shown in Figs. 4 and 5 were therefore explored. The first approach (Fig. 4) used a clear acrylic tube which allowed the entire coupon to be viewed during the fatigue test. The second approach (Fig. 5), using a plastic bag pouch sealed with waterproof tape, proved to be the more satisfactory of the two because it allowed the use of the standard hydraulic jaws to grip the coupons.

Most of the fatigue testing was carried out at constant amplitude in tension-tension $(R=0.1)$ mode. However, some coupons were subjected to a 2-block test regime where a first block of fatigue cycling between 15.5 and $155 \mathrm{MPa}$ was carried out for 10,000 cycles and then the coupons were tested to failure in a constant amplitude $(R=0.1)$ fatigue test to $180 \mathrm{MPa}$ maximum stress.

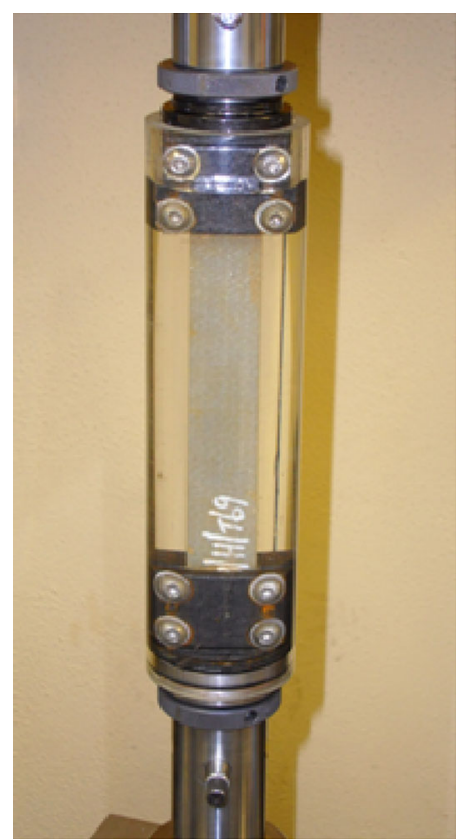

Fig. 4 Immersed fatigue test setup, acrylic tube with O-ring seal

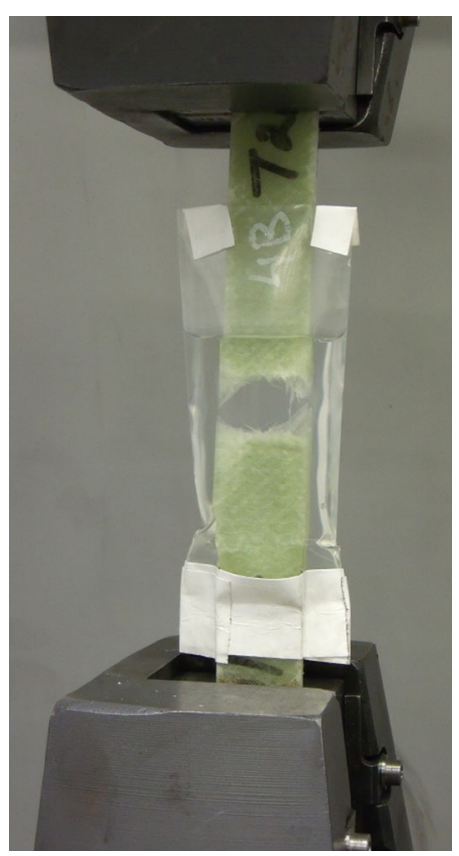

Fig. 5 Immersed fatigue test setup, polyethylene pouch with waterproof tape

\section{Results}

\subsection{Water Uptake During Immersion Ageing}

Figure 6 shows the \% weight of water absorbed by the epoxy/E-glass coupons while they were immersed in the ageing tanks at $30{ }^{\circ} \mathrm{C}$ and at room temperature. The 


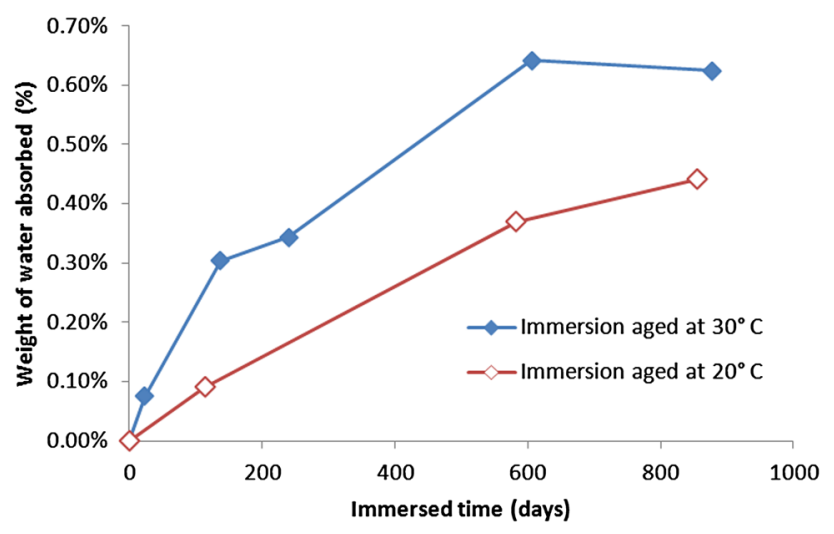

Fig. 6 Weight of water absorbed by Epoxy/E-glass composite during water immersion ageing

increased diffusion activity stimulated by the higher temperature has enabled the coupons immersed in $30{ }^{\circ} \mathrm{C}$ water to absorb water more quickly and become saturated at approximately $0.60 \%$ moisture. The coupons at room temperature absorbed water more slowly and had not become saturated by the end of the immersion period. Figure 7 shows a similar graph for the vinyl-ester/E-glass coupons. In this case, the maximum moisture saturation is just slightly less than $0.2 \%$. Again the lower temperature ageing takes longer to saturate. The vinyl-ester/E-CR glass coupons on average absorbed $0.16 \%$ of their weight in water during 21 months immersed in $40^{\circ}$ water. It should be noted that the \% moisture absorbed by both the epoxy and vinyl-ester composite coupons is amongst the lowest reported in the literature. The reasons for this are probably twofold. Firstly, the particular polymers chosen for this work are recommended by their manufacturers for use in immersed applications and they have presumably been developed to minimise water absorption. Secondly, the laminates from which the coupons were taken had a low void content. A void measurement study found $0.22 \%$ void content in the epoxy/E-glass material and did not find any voids in a cross-section of the vinyl-ester/E-glass material when viewed at $175 \mathrm{X}$ under a microscope. Figure 8 shows an optical micrograph of typical voids in the test coupons.

\subsection{Tensile Strength of Wet and Dry Coupons}

Figure 9 shows the results of quasi-static tensile testing of wet and dry vinyl-ester/E-glass and vinyl-ester/E-CR glass QI coupons. The wet coupons had been immersion-aged in $40{ }^{\circ} \mathrm{C}$ water for up to 30 months. The dry coupons were stored at room temperature for a similar time before testing. The measured vinyl-ester/E-CR glass strength results have been adjusted to give equivalent $50 \%$ volume fraction values for comparison with the other materials. The

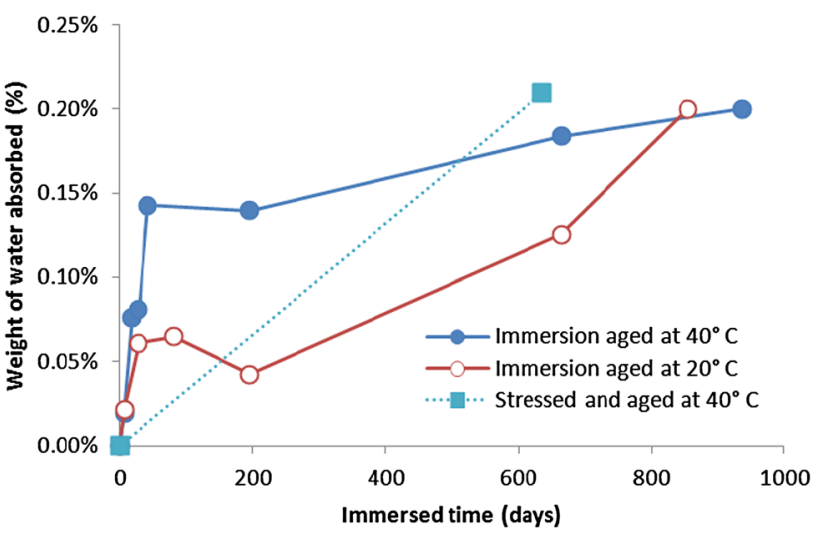

Fig. 7 Weight of water absorbed by Vinyl-ester/E-glass composite during water immersion ageing

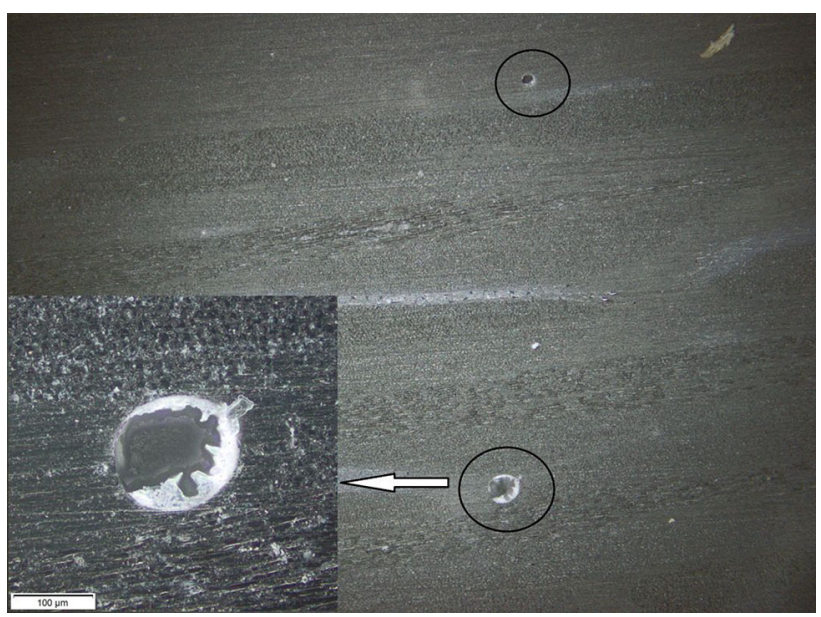

Fig. 8 Optical micrographs of typical voids in test specimens

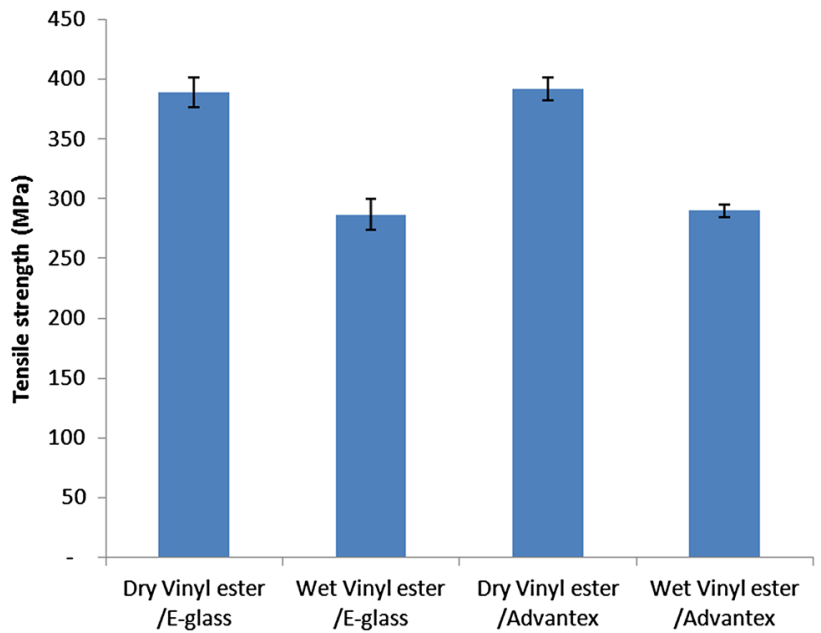

Fig. 9 Tensile strength of wet and dry vinyl-ester composite materials 
results show that the E-glass and E-CR glass coupons have approximately equal dry strength. The results also show that both E-glass and E-CR glass fibre-reinforced vinylester composites lose $26 \%$ of their tensile strength due to the immersion ageing. Reports in the literature find similar ( $\sim 20 \%$ ) decreases in static failure strength of vinyl-ester/ E-glass composites after water immersion ageing [22] [16].

\subsection{Fatigue Test Results}

Figure 10 shows the stress-life results of the fatigue testing of epoxy/E-glass QI coupons in tension-tension mode ( $R=0.1$ ) for both the wet and dry coupons. The number of cycles shown corresponds in general to complete fracture of the specimen, as shown in Fig. 11. The dry coupons were stored at room temperature for 29 months and tested in air at room temperature. The wet coupons were immersed for 29 months in $30{ }^{\circ} \mathrm{C}$ water and tested while immersed in the water pouch shown in Fig. 5, at room temperature. The results show a significant decrease in fatigue strength for the water-aged immersed coupons compared to the dry coupons; for example, at high stresses the wet fatigue strength is $20-25 \%$ lower and at high cycles the wet fatigue strength is $8 \%$ lower. Therefore, the effect of water saturation on the fatigue strength of QI GFRP is stress-level dependent. The actual reduction in fatigue life of a structure due to immersed service will therefore depend on the spectrum of fatigue stress cycles it experiences while in service.

Figure 12 shows the results of fatigue tests on wet and dry coupons of vinyl-ester/E-glass for both the constant amplitude fatigue test at $180 \mathrm{MPa}$ (maximum stress) and the 2-block test $(10,000$ cycles at $155 \mathrm{MPa}$ followed by fatigue at $180 \mathrm{MPa}$ ). The first point of interest is that these results show no significant difference in constant amplitude fatigue life between wet and dry coupons (approximately $7 \times 10^{3}$ cycles for both). While this is only a single point on the stress-life curve it does indicate that the very low

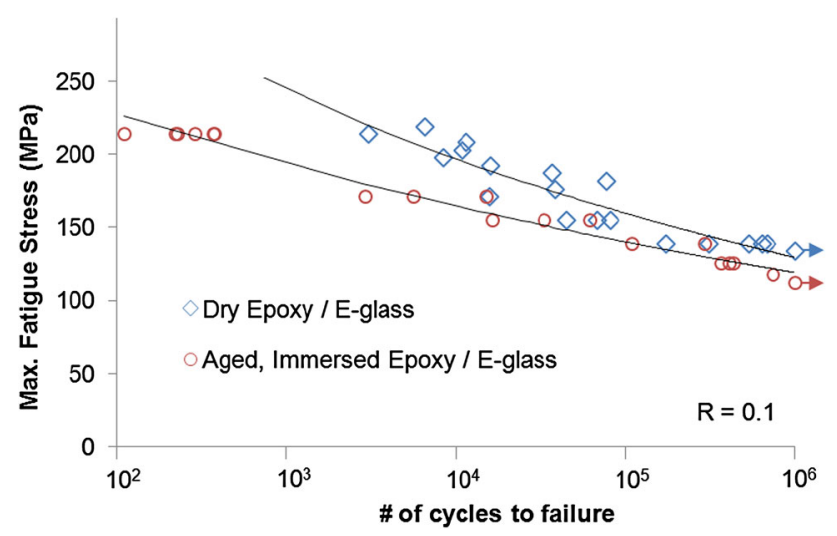

Fig. 10 Stress-life curves for wet and dry epoxy/E-glass in $R=0.1$ fatigue tests

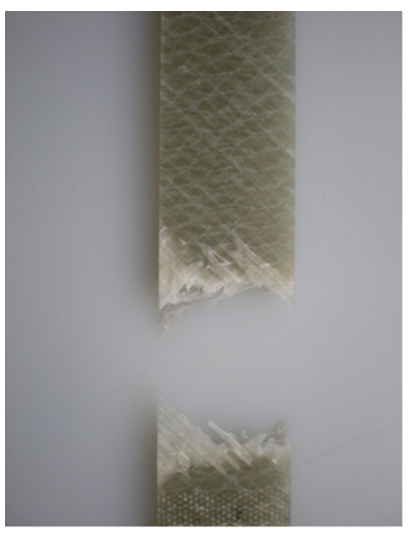

$0.81 \%$ Initial strain, $\mathrm{R}=0.1$

\# of cycles to failure 52,041

(a)

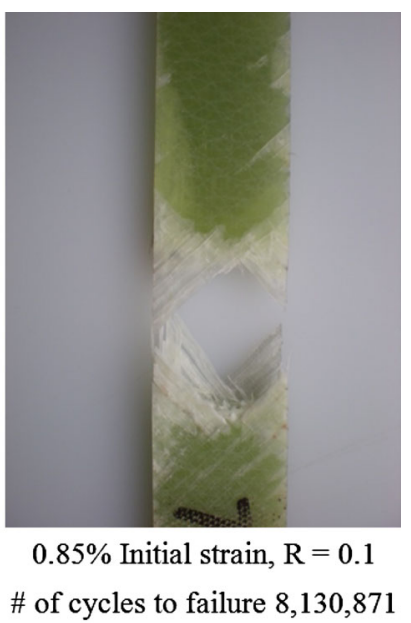

(b)
Fig. 11 Photographs of fractured test specimens

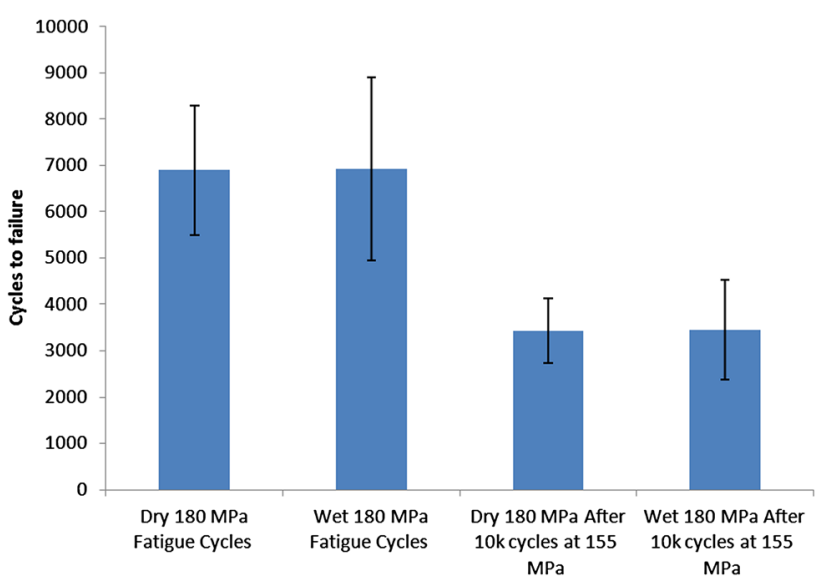

Fig. 12 Wet and dry constant amplitude, $R=0.1$, fatigue tests compared to wet and dry two-block fatigue tests on QI vinyl-ester/Eglass coupons

levels of moisture absorbed by these coupons $(0.2 \%)$ have very little impact on the fatigue strength.

The second point of interest in Fig. 12 is a comparison between the single block (constant amplitude) tests and the two-block tests. This result shows that cycling the coupons for 10,000 cycles at $155 \mathrm{MPa}$ (the first block of cycles) reduces the number of cycles-to-failure in the second block (at $180 \mathrm{MPa}$ ) by approximately $3.5 \times 10^{3}$ cycles, i.e. about half the average fatigue life at $180 \mathrm{MPa}$. A Miner's rule linear cumulative damage calculation indicates that the first block of 10,000 cycles consumes $55 \%$ of the fatigue life (damage $=0.55$ ) and therefore the average Miner's cumulative damage to failure of the coupons is 1.05. While the individual tests have Miner's damage values ranging from 0.87 to 1.47 at failure, the average value of 1.05 gives some confidence in the use of Miner's rule. 


\subsection{Stressed Ageing Tests}

Water absorption levels in the stressed and immersion-aged vinyl-ester/E-glass coupons could not be measured while they were in the stressing rig and therefore only the final moisture absorption value $(0.21 \%$ by weight $)$, when they were removed from the rig, was determined. This value is plotted in Fig. 7 for comparison with the water uptake of the coupons which were not stressed during immersion ageing and shows that there is no indication of extra water absorption due to the applied stress. Creep strain was also measured during this stressed coupon test by monitoring the overall length of the coupons. There was a small amount of creep $(0.05 \%)$ in both the wet and dry coupons which underwent the same stressed test procedure.

Figure 13 shows the results of fatigue testing of coupons which had been wet or dry stress aged. In order to show a comparison based on the total loading experienced by the coupons, using Miner's rule, the initial 10,000 cycles precracking of the stress-aged specimens (see Sect. 2.3) have been converted to an equivalent 3778 cycles at $180 \mathrm{MPa}$ and added to the cycles-to-failure result of the fatigue test after stress ageing. The results show that maintaining the coupons under a constant stress of $43 \mathrm{MPa}$ during 21 month immersion in $40{ }^{\circ} \mathrm{C}$ water reduces the 6000 cycles-to-failure fatigue strength of vinyl-ester/E-glass by approximately $10 \%$.

\subsection{Fatigue of Vinyl-Ester/E-CR Glass Coupons}

Wet and dry vinyl-ester/E-CR glass coupons were tested in fatigue at $186 \mathrm{MPa}$ (maximum stress), $R=0.1$ and $4 \mathrm{~Hz}$. The results show an average reduction in mean cycles-tofailure from 4052 to 3014 due to immersion ageing in

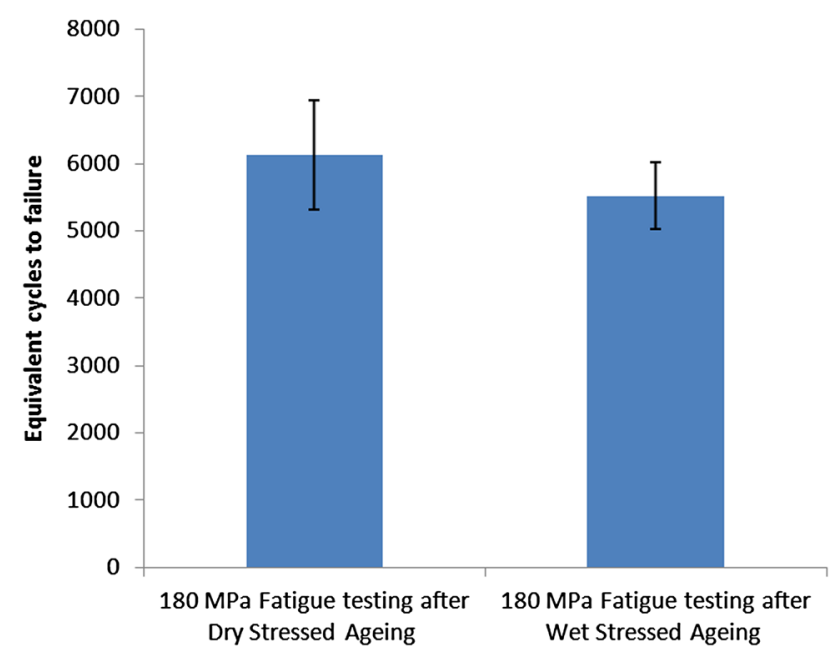

Fig. 13 Fatigue life of dry stress-aged and wet stress-aged vinylester/E-glass coupons
$40{ }^{\circ} \mathrm{C}$ water for 20 months. This reduction in life can be compared to the corresponding results for the vinyl-ester/ E-glass coupons which showed a negligible reduction in life due to water immersion ageing when tested at approximately the same stress level (cf. Figure 9).

\subsection{Stiffness Degradation}

Plasticisation of the matrix material due to water saturation is expected to reduce its modulus and thereby reduce the tensile modulus of the composite material. In addition, fatigue cycling causes significant reduction in stiffness of QI GFRP due to inter-fibre fracture and fibre breakage [26]. Water saturation may exacerbate these effects. A study was first carried out to compare the quasi-static tensile modulus of dry epoxy/E-glass coupons and the wet coupons which were immersion-aged in $30{ }^{\circ} \mathrm{C}$ water for 29 months. Modulus values were calculated from the load cell and crosshead displacement data acquisition during the initial extension phase of the first fatigue cycle of the fatigue tests. All tests were carried out on the same tensile test machine with the same setup in a temperature-controlled room. The initial extension ramp was completed in $10 \mathrm{~s}$ and almost 1000 data points were recorded for each coupon during this period. A linear fit to the data between 0 and $0.05 \%$ strain was used to calculate the zero load extension and, following that, a linear fit to the stress strain-curve between 0.05 and $0.25 \%$ (per ASTM D $3030 \mathrm{M}-08$ ) was performed, to establish the modulus of the material. A comparative calibration with extensometer data was carried out and a correction for machine stiffness was incorporated into the method. The results, shown in Fig. 14, indicate that the average modulus of the wet coupons is only $1.1 \%$ lower than that of the dry coupons. Classical laminate theory analysis of a quasi-isotropic layup similar to the test coupons predicts that a decrease in matrix modulus of $3.5 \%$ would result in a $1.1 \%$ decrease in tensile modulus of the coupon.

The left hand side of Fig. 15 shows the measured evolution in quasi-static modulus of the composite material as the load increases during the first half of the first fatigue cycle for a number of wet and dry coupons at three different stress levels. The graph shows that quasi-static modulus of the material decreases with increasing strain during the first half cycle due to matrix micro-cracking and minor fibre breakages. The modulus of the material is therefore initially a little greater than the value calculated between 0.5 and $0.25 \%$ strain using the ASTM standard. This degradation in modulus in the first half cycle can be significant at high stresses as shown here for the case where the maximum stress is $219 \mathrm{MPa}$; however, there is no indication of additional degradation in the water-saturated coupons. 


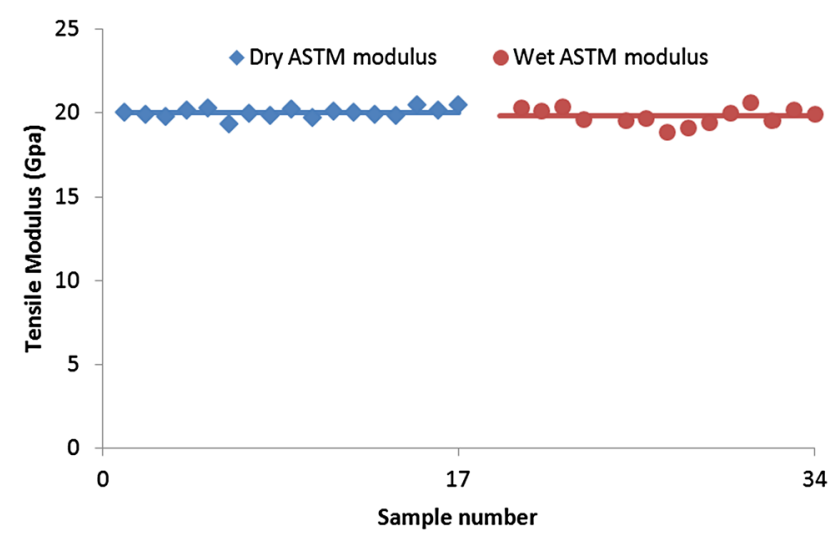

Fig. 14 Tensile modulus of dry and water-aged quasi-isotropic epoxy/E-glass coupons

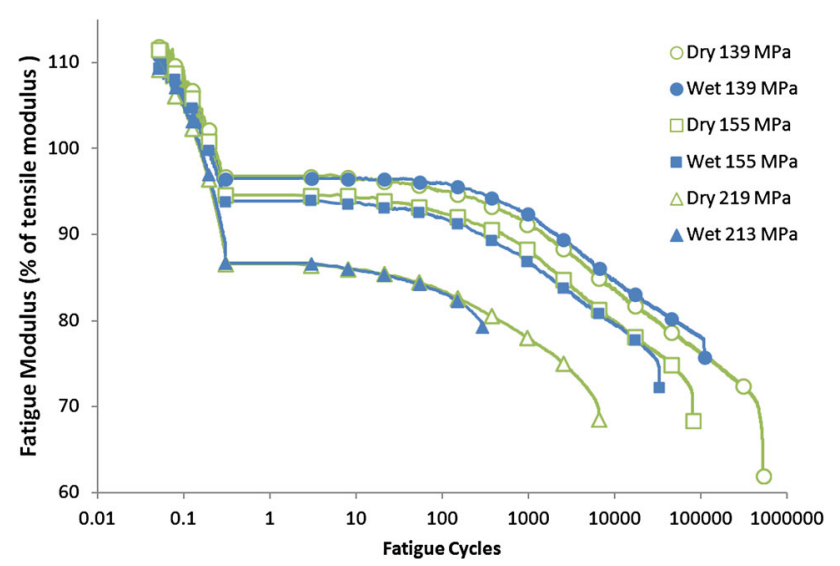

Fig. 15 Measured modulus degradation during initial loading phase (cycles $<0.5$ ), and subsequent fatigue cycling at $R=0.1$ of QI epoxy/ E-glass

The fatigue modulus - defined here as the slope of a line which connects the minimum stress-strain point in a fatigue cycle with the maximum stress-strain point in the cycle-was also continuously monitored during the fatigue tests, and the results are displayed in Fig. 15 from cycle two onward. Note that the markers are for identification only; the lines shown are the continuous data. The graph shows that the overall degradation in modulus before failure for the dry material is similar for all stress levels at approximately $30 \%$. The graph also shows that wet coupon stiffness and dry coupon stiffness decay in the same way during fatigue cycling. The only significant difference is that the wet coupons consistently fail at lower numbers of cycles. Therefore, it appears that water saturation does not have any significant effect on the stiffness of composite materials.

The results described above provide some confidence that GFRP materials will remain competitive for use in tidal turbine blade structures. While there is some degradation in the material fatigue strength due to water saturation it is a limited effect, particularly at high cycle life. Given that a 10-rpm turbine will experience at least 50 million cycles in a 20-year design life it is to be expected that the effect of water saturation on the fatigue life would mirror that at the upper end of the fatigue-life curve.

\section{Conclusions}

The accelerated ageing procedure adopted in this study has simulated the immersion of GFRP materials in $12{ }^{\circ} \mathrm{C}$ seawater for a period of 18 years by immersing coupons of the materials in warm water $\left(30\right.$ and $\left.40{ }^{\circ} \mathrm{C}\right)$ for approximately 2.5 years. The coupons absorbed relatively small amounts of water ( 0.2 to $0.6 \%)$ during immersion due to the materials chosen and fabrication procedures adopted. These materials and processes are therefore expected to be good candidates for use in tidal turbine blades.

After completion of the immersion ageing procedure the "wet" material coupons were subjected to a number of mechanical tests and their results are compared to similar tests on unaged "dry" specimens.

Fatigue testing of wet epoxy/E-glass coupons found that the fatigue strength of the material was significantly degraded by water immersion ageing. For example, for a fatigue life of 1000 cycles, the wet fatigue strength is $20 \%$ less than the dry fatigue strength, and for a life of 1 million cycles the wet fatigue strength is $8 \%$ less, so that the effect is also stress-level dependent.

The results showed a negligible difference $(1 \%)$ in quasi-static tensile modulus between wet and dry QI epoxy/E-glass coupons. Results also showed no difference in the evolution of fatigue modulus between wet and dry coupons during fatigue testing.

Tensile strengths of wet vinyl-ester matrix coupons, with either E-glass or E-CR glass-glass fibres, were found to be $25 \%$ less than equivalent dry coupons but fatigue strength near $5 \times 10^{3}$ cycles-to-failure was either unaffected or only slightly degraded by moisture uptake.

Tests on QI vinyl-ester/E-glass coupons which were stressed during immersion ageing found a $10 \%$ reduction in fatigue strength compared to similar coupons which were not immersed in water.

Finally, it is hypothesised that the impairment of the mechanical properties due to prolonged immersion in water is due to reduction in adhesion between the fibres and the matrix. Future work, including micro-scale investigations, will investigate this in more detail.

Acknowledgments Thanks to EireComposites for their advice and assistance in preparing the laminates and to Composites Testing Laboratory (CTL) for coupon preparation and fatigue testing. This 
material is based upon works supported by the Science Foundation Ireland under Grant No. SFI/12/RC/2302.

Open Access This article is distributed under the terms of the Creative Commons Attribution 4.0 International License (http://crea tivecommons.org/licenses/by/4.0/), which permits unrestricted use, distribution, and reproduction in any medium, provided you give appropriate credit to the original author(s) and the source, provide a link to the Creative Commons license, and indicate if changes were made.

\section{References}

1. Grogan DM, Leen SB, Kennedy CR, Brádaigh CMÓ (2013) Design of composite tidal turbine blades. Renewable Energy 57:151-162

2. Carrillo C, Obando Montaño AF, Cidrás J, Díaz-Dorado E (2013) Review of power curve modelling for wind turbines. Renew Sustain Energy Rev 21:572-581

3. Davies P, MazEas F, Casari P (2001) Sea water aging of glass reinforced composites: shear behaviour and damage modelling. J Compos Mater 35(15):1343-1372

4. DeIasi R, Whiteside JB (1978) Effects of moisture on epoxy resins and composites. In: Vinson JR (ed) Advanced composite materials: environmental effects. ASTM International, West Conshohocken

5. Adamson MJ (1980) Thermal expansion and swelling of cured epoxy resin used in graphite/epoxy composite materials. J Mater Sci 15(7):1736-1745

6. Shen C-H, Springer GS (1976) Moisture absorption and desorption of composite materials. J Compos Mater 10(1):2-20

7. Bond DA, Smith PA (2006) Modeling the transport of lowmolecular-weight penetrants within polymer matrix composites. Appl Mech Rev 59(5):249

8. Thomason JL (1995) The interface region in glass fibre-reinforced epoxy resin composites: 2 . Water absorption, voids and the interface. Composites 26(7):477-485

9. Ó Brádaigh CM, Doyle A, Doyle D, Feerick PJ (2011) Electrically-heated ceramic composite tooling for out-of-autoclave manufacturing of large composite structures. SAMPE J 47(4):6-14

10. Miller D, Mandell JF, Samborsky DD, Hernandez-Sanchez BA, Griffith DT (2012) Performance of composite materials subjected to salt water environments. In 2012 AIAA SDM Wind Energy Session, Hawaii

11. BenDaly H, Harchay M, Belhadjsalah H, Boukhili R (2009) Experimental characterization and numerical simulation of the humidity absorption process in glass reinforced composites under dissymmetric exposure conditions. Polym Compos 30(12):18251836

12. Baley C, Grohens Y, Busnel F, Davies P (2004) Application of interlaminar tests to marine composites. Relation between glass fibre/polymer interfaces and interlaminar properties of marine composites. Appl Compos Mater 11(2):77-98

13. Martin RH (1995) Composite materials: fatigue and fracture. ASTM International, West Conshohocken

14. Hull D, Clyne TW (1996) An introduction to composite materials, 2nd edn. Cambridge University Press, Cambridge

15. Mourad A-HI, Abdel-Magid BM, El-Maaddawy T, Grami ME (2010) Effect of seawater and warm environment on glass/epoxy and glass/polyurethane composites. Appl Compos Mater 17(5):557-573

16. HN Murthy, M Sreejith, M Krishna, SC Sharma, TS Sheshadri (2009) Seawater durability of epoxy/vinyl ester reinforced with glass/carbon composites. J Reinf Plast Compos p 07316844 09335451

17. Antoon MK, Koenig JL (1980) The phase in structure and moisture stability of the matrix glass-reinforced epoxy composites. J Macromol Sci Part C Polym Rev 19(1):135-173

18. Pauchard V, Chateauminois A, Grosjean F, Odru P (2002) In situ analysis of delayed fibre failure within water-aged GFRP under static fatigue conditions. Int J Fatigue 24(2-4):447-454

19. Buehler FU, Seferis JC (2000) Effect of reinforcement and solvent content on moisture absorption in epoxy composite materials. Compos Part A 31(7):741-748

20. Harris B (1999) Engineering composite materials. The Institute of Materials, London

21. Segovia F, Salvador MD, Sahuquillo O, Vicente A (2007) Effects of long-term exposure on e-glass composite material subjected to stress corrosion in a saline medium. $J$ Compos Mater 41(17):2119-2128

22. Gellert EP, Turley DM (1999) Seawater immersion ageing of glass-fibre reinforced polymer laminates for marine applications. Compos A Appl Sci Manuf 30(11):1259-1265

23. Boisseau A, Davies P, Thiebaud F (2013) Fatigue behaviour of glass fibre reinforced composites for ocean energy conversion systems. Appl Compos Mater 20(2):145-155

24. Kennedy CR, Leen SB, Ó Brádaigh CM (2012) A preliminary design methodology for fatigue life prediction of polymer composites for tidal turbine blades. Proc Instit Mech Eng Part L 226(3):203-218

25. Purnell P, Cain J, van Itterbeeck P, Lesko J (2008) Service life modelling of fibre composites: a unified approach. Compos Sci Technol 68(15-16):3330-3336

26. Kennedy CR, Ó Brádaigh CM, Leen SB (2013) A multiaxial fatigue damage model for fibre reinforced polymer composites. Compos Struct 106:201-210 